\title{
Linoleic Acid Increases Prostaglandin E2 Release and Reduces Mitochondrial Respiration and Cell Viability in Human Trophoblast-Like Cells
}

\author{
Nirajan Shrestha ${ }^{\mathrm{a}}$ James SM Cuffe ${ }^{\mathrm{a}}$ Olivia J Holland ${ }^{\mathrm{a}}$ Anthony V Perkins ${ }^{\mathrm{a}}$ \\ Andrew J McAinch ${ }^{b, c}$ Deanne H. Hryciw ${ }^{b, d}$ \\ aSchool of Medical Science, Griffith University, Southport, Australia, 'Institute for Health and Sport, \\ Victoria University, Melbourne, Australia, 'Australian Institute for Musculoskeletal Science (AIMSS), \\ Victoria University, St. Albans, Australia, 'School of Environment and Science, Griffith University, \\ Nathan, Australia
}

\section{Key Words}

Linoleic acid • Placenta • Inflammation • Fatty acid transport protein • Fatty acid binding protein

\begin{abstract}
Background/Aims: The omega 6 fatty acid (FA) linoleic acid (LA) is required for embryonic development; however, omega 6 FAs can alter cellular metabolism via inflammation or modulation of mitochondrial function. Fetal LA is obtained from the maternal diet, and FAs are transported to the fetus via placental FA transporters (FATPs) and binding proteins (FABPs), but specific proteins responsible for LA transport in placental trophoblasts are unknown. Dietary LA consumption is increasing, but the effect of elevated LA on trophoblast function is not clear. Methods: Swan71 trophoblasts were exposed to physiological and supraphysiological concentrations of LA for 24 hours. Quantification of mRNA was determined using real time $\mathrm{PCR}$, and protein concentration was determined by Western blot analysis. Cell viability, citrate synthase activity and mitochondrial respiration were determined. Results: Exposure to 300 and $500 \mu \mathrm{M}$ LA increased FATP1 and FATP4 mRNA expression. $500 \mu \mathrm{M}$ LA increased FATP1 and FATP4 protein expression. Exposure to $500 \mu \mathrm{M}$ increased FABP5 mRNA expression, while exposure to 100 to $500 \mu \mathrm{M}$ LA decreased FABP3 mRNA expression. 300 and $500 \mu \mathrm{M}$ LA decreased FABP3 protein expression. Cell viability was decreased by exposure to LA (100 to $1000 \mu \mathrm{M}$ ). Citrate synthase activity and routine mitochondrial respiration were significantly decreased by exposure to 300 and $500 \mu \mathrm{M} \mathrm{LA}$, and maximal respiration and spare respiratory capacity were decreased by exposure to 100 to $500 \mu \mathrm{M}$ LA. 300 and $500 \mu \mathrm{M}$ LA increased reactive oxygen species generation in human trophoblasts. Moreover, exposure to 300 and $500 \mu \mathrm{M}$ LA decreased IL- 6 secretion. Exposure to $500 \mu \mathrm{M}$ LA increased $I L-8, N F-\kappa B$ and PPAR- $\gamma$ mRNA expression, but decreased NF-KB protein expression. $300 \mu \mathrm{M}$ LA decreased IL-8 protein


expression. Further, exposure to 100 to $500 \mu \mathrm{M} \mathrm{LA}$ increased prostaglandin $\mathrm{E}_{2}$ and leukotriene $\mathrm{B}_{4}$ release. Conclusion: Exposure to LA decreases cell viability, alters mRNA expression of FA transport related proteins, mitochondrial respiration and function, and inflammatory responses in trophoblasts. These findings may have implications on placental function when women consume high levels of LA.

(C) 2019 The Author(s). Published by Cell Physiol Biochem Press GmbH\&Co. KG

\section{Introduction}

The omega 6 (n-6) fatty acid (FA), linoleic acid (LA; 18:2n-6; cis, cis-9, 12-octadecadienoic acid), is a long chain polyunsaturated fatty acid (LCPUFA). Elevated concentrations of LA are known to be pro-inflammatory and pro-oxidative [1]. In the Western diet, LA consumption has increased to three times the recommended daily intake between 1961 and 2009 [2]. This increase is likely a consequence of greater LA dietary availability; for example, in Australia, LA availability in the diet has increased by $120 \%$ [2] and in the USA by $158 \%$ [3]. Vegetable oils such as corn and soybean are high in LA [4], thus the increased consumption of LA may be in part due to dietary guidelines that suggest the replacement of animal fats with polyunsaturated fatty acid (PUFA) [5]. In most dietary recommendations, a distinction for which types of PUFA should be consumed has often not been made clear. Specific consumption of the n-3 PUFAs, that are not pro-inflammatory, has not been disseminated to the public, with the recommended ratio of levels of consumption of $n-6 / n-3$ PUFA is $1: 1-2: 1$. However, in recent years the level of consumption of the ratio of n-6/n-3 PUFA has increased to more than 10:1 in US populations [6]. Consequently, LA plasma concentration in a person in a Westernised country is estimated to be $280-5000 \mu \mathrm{M}$ (average concentration $2000 \mu \mathrm{M}$ ) [7].

LA has pro-inflammatory properties as it is precursor for pro-inflammatory metabolites, and is also associated with obesity and metabolic disease [8]. LA can be metabolised by elongation and desaturation to produce $\gamma$-linoleic acid and arachidonic acid (AA). AA can be further metabolised into prostaglandins and leukotrienes, which are pro-inflammatory when produced in excess [9]. Thus, elevated consumption of LA may lead to an increase in circulating pro-inflammatory mediators [10], as well as greater adiposity [11], potentially damaging organs and resulting in metabolic disease risk.

Optimal maternal nutrition during pregnancy is critical for fetal development, and a suboptimal intrauterine environment can impact fetal development [12]. Disruption to fetal organ development due to insufficient placental transport of nutrients is linked to organ dysfunction, and an increased risk of disease later in life [13, 14]. LCPUFA concentrations for optimal intrauterine development are key to the growth of cell membranes, membrane permeability and metabolic processes [15]. Although LA levels have been well studied in non-pregnant individuals, the healthy concentration of LA in maternal blood is currently debated. For example, the maternal circulating LA concentration during pregnancy have been estimated to be $30 \mu \mathrm{M}$ [16], $45 \mu \mathrm{M}$ [17] and $~ 100 \mu \mathrm{M}$ [18]. Women consuming an elevated $\mathrm{n}-3$ diet the concentration is $\sim 650 \mu \mathrm{M}$ [19] and maternal erythrocyte LA concentration being reported to be $\sim 200 \mu \mathrm{M}[20]$. Importantly, fetal requirements of LCPUFA are that it must be obtained from the diet, with fetal supply determined via maternal consumption [21].

Transfer of nutrients from maternal to fetal systems via the placenta depends on transport across a number of cell layers. FA are thought to be transported across the placenta by both simple and facilitated diffusion, although the relative amount of simple vs facilitated diffusion is debated [22]. Facilitated transport of FA from the maternal to the fetal circulation via transmembrane proteins (FATPs and FAT/CD36) and intracellular binding proteins (FABPs) [23]. Transport of FAs can be regulated by changes in FATPs and FABPs, and these proteins are responsive to further FA metabolism [24]. To date, the specific regulation of fatty acid transport proteins by LA has not been investigated or characterised in placental epithelial cells. FA from the maternal circulation can bind to FATPs in the syncytiotrophoblast membrane allowing endocytosis and transfer to intracellular FABPs. FA are thought to bind 


\section{Cellular Physiology

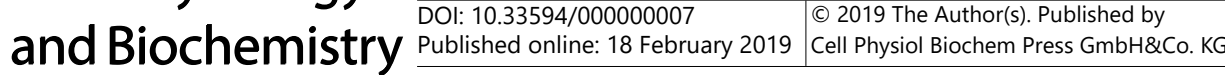 \\ Shrestha et al.: Linoleic Acid Alters Viability and Mitochondrial Respiration in Trophoblasts}

to fetal FATPs in the endothelial fetal capillary cell membrane, allowing transport to the fetal circulation [25]. The FABPs are thought to not only regulate cytosolic transport between membrane bound transporters, but also traffic FA within the syncytiotrophoblast for cellular utilization of FA. Recently, a combined computational-experimental model proposed that trophoblasts metabolize a significant fraction of fatty acids taken up by the microvillous membrane and delivery to the fetus is therefore regulated by both placental metabolism and basal membrane transfer [22]. However, the factors determining FA transport across the trophoblast are still poorly understood.

When bound to intracellular FABPs, FAs have the capacity to alter various aspects of cellular function, namely gene transcription, mitochondrial function and lipid storage [26]. Excessive dietary LA has the capacity to produce elevated concentrations of pro-inflammatory markers in rats [10]; and in human endothelial cells, LA selectively induces an inflammatory environment [27]. Aberrant placental inflammation is associated with placental damage; with loss of function and release of inflammatory mediators leading to fetal organ damage [28]. Previous studies have shown that elevated concentrations of other FAs may have a deleterious effect on the placenta. Specifically, exposure to elevated concentrations of palmitic acid induces inflammatory responses through reactive oxygen species (ROS) production in human placental trophoblast cells [29]. Further, in sheep, consumption of a diet with elevated concentrations of LA increases circulating maternal prostaglandin concentrations [30]. In human primary trophoblasts, there is significant reduction in mitochondrial respiration with increasing maternal obesity [31]. Obesity is associated with elevated maternal LA consumption, albeit amid a number of other deleterious dietary changes. The potential underlying molecular mechanism linking LA and inflammation could be via a number of pathways, with additional proteins, such as peroxisome proliferator activated receptorgamma (PPAR- $\gamma$ ) which regulates fatty acid transport in human placental trophoblast [32], likely to be involved.

The current study aimed to investigate the effects of exposure to elevated concentrations of LA on trophoblast function and the expression of FA transport associated genes. We hypothesised that exposure to elevated concentrations of LA would alter specific FATPs and FABPs, and trophoblast inflammatory targets, as well as decrease cellular viability and mitochondrial function.

\section{Materials and Methods}

\section{Materials}

LA, fatty acid free bovine serum albumin (FA free BSA) and 3-(4, 5-dimethylthiazol-2-yl)-2, 5-diphenyltetrazolium bromide (MTT) reagent were purchased from Sigma-Aldrich, Australia. Dulbecco's Modified Eagle's Medium (DMEM)/F12, Fetal Bovine Serum (FBS), trypsin and penicillin-streptomycin solution were purchased from Gibco, US.

\section{Cell culture and drug treatment}

The trophoblast-like Swan71 cell line (kindly provided by Professor Gil Mor, Yale University) was cultured in DMEM supplemented with 10\% FBS and 1\% penicillin and streptomycin. Straszewski-Chavez et al. originally detailed the isolation and characterization of the Swan71 cell line [33]. Cells (at 30-40 passage) were cultured in humidified incubator at $37^{\circ} \mathrm{C}$ with $5 \% \mathrm{CO}_{2}$. LA and BSA complex was prepared in the molar ratio of $5: 1$ and incubated at $37^{\circ} \mathrm{C}$ for 15 minutes. Cells were transferred into serum free media for 2 hours after they were approximately $70 \%$ confluent. After 2 hours, cells were treated with vehicle control (BSA $+0.1 \%$ ethanol) or different concentrations of LA-BSA complex $(25,100,200,300,400,500$ and $1000 \mu \mathrm{M})$ for 24 hours. 


\section{Cellular Physiology Cell Physiol Biochem 2019;52:94-108 \\ \begin{tabular}{l|l|l}
\hline DOI: 10.33594/000000007 & (c) 2019 The Author(s). Published by
\end{tabular} \\ and BiOChemistry Published online: 18 February 2019 Cell Physiol Biochem Press GmbH\&Co. KG \\ Shrestha et al.: Linoleic Acid Alters Viability and Mitochondrial Respiration in Trophoblasts}

Cell viability assay

Cell viability was measured using an MTT assay (Sigma Aldrich, St. Louis, MO, USA). Briefly, cells were seeded at an initial density of 15, 000 cells per well in 96 well culture plates and incubated. After cells were approximately $70 \%$ confluent, cells were incubated in media containing the vehicle control or the various concentrations of LA described above for 24 hours. Thereafter, cells were incubated in $1 \mathrm{mg} / \mathrm{ml}$ of MTT reagent for 4 hours. The media with MTT reagent was removed and dimethyl sulfoxide (DMSO) added to each well for 30 minutes to dissolve the formazan compound. The absorbance was measured spectrophotometrically at $540 \mathrm{~nm}$ using Infinite M Plex microplate reader (TECAN, Switzerland).

\section{Quantitative polymerase chain reaction}

Total RNA was extracted using an RNeasy mini kit (Qiagen) following manufacturer's guidelines. Reverse transcription of RNA to synthesize complementary DNA was performed using an iScript gDNA clear cDNA synthesis kit (Biorad) following manufacturer's guidelines. Quantitative PCR was performed using SYBR green master mix (Biorad) following manufacturer's guidelines. Gene expression was quantified using the $2^{-\Delta \Delta C \mathrm{~T}}$ method normalised to the geometric mean of $\beta$-actin and $\beta$-microglobulin as housekeeping genes. These housekeeping genes were shown to be stably expressed within this cell line and were unaffected by treatment (data not shown). All the primers used are KiCqStart predesigned optimized primers from Sigma- Aldrich.

Citrate synthase activity assay

Citrate synthase activity was determined in total protein following published methodology [34].

\section{Measurement of cellular respiration}

Cellular respiration after LA treatment was measured using an Oxygraph $2 \mathrm{~K}$ instrument (OROBOROS Instruments, Innsbruck, Austria). Briefly, after 24 hours of LA or vehicle treatment, cells were harvested by routine trypsin digestion and live cells counted via trypan blue exclusion [35]. Live cells were resuspended at one million cells per $\mathrm{mL}$ in appropriate culture media (serum free DMEM/F12 media containing LA or vehicle). Two $\mathrm{mL}$ of the cell suspension was added to the oxygraph chamber with the temperature set to $37^{\circ} \mathrm{C}$ and oxygen flux normalised to cell concentration measured. (1) Routine or basal mitochondrial respiration was measured, and then the following cell permeable substrates and inhibitors were used to determined respiration level: (2) LEAK state was determined by inhibition of ATP synthase with oligomycin (2.5 $\mu \mathrm{M}),(3)$ the electron transport system (ETS) maximum capacity was determined by titration of carbonyl cyanide 3-chlorophenylhydrazone (CCCP; $0.5 \mu \mathrm{M}$ ) to dissipate membrane potential and uncouple EST complexes, and (4) residual oxygen consumption (ROC) was determined by inhibiting ETS Complex I with rotenone $(0.5$ $\mu \mathrm{M}$; all reagents from Sigma-Aldrich, Australia). Routine, LEAK, and maximum capacity fluxes are expressed minus ROC. The respiration data was normalized to cell number and expressed as fold changes compared with vehicle control group. Spare respiratory capacity was calculated by subtracting routine respiration from maximum capacity.

\section{Hydrogen peroxide assay}

The reactive oxygen species (ROS) generation in Swan71 trophoblasts after the treatment of LA was measured using am Amplex® Ultra Red (AUR; Thermo Fisher Scientific) hydrogen peroxide $\left(\mathrm{H}_{2} \mathrm{O}_{2}\right)$ assay. AUR reagent (10-acetyl-3, 7-dihydroxyphenoxazine) reacts with $\mathrm{H}_{2} \mathrm{O}_{2}$ in a 1:1 stoichiometry to produce the red-fluorescent oxidation product, resorufin. Briefly, protein samples extracted from cells were mixed with $10 \mu \mathrm{M}$ AUR, $5 \mathrm{U} / \mathrm{mL}$ superoxide dismutase (SOD; Sigma-Aldrich, Australia), $1 \mathrm{U} / \mathrm{mL}$ horseradish peroxidase (HRP; Sigma-Aldrich, Australia) and Mir05 buffer (0.5 mM EGTA, $3.0 \mathrm{mM} \mathrm{MgCl}{ }_{2}$ [Sharlab, Spain], $60 \mathrm{mM}$ K-lactobionate, $10 \mathrm{mM} \mathrm{KH} \mathrm{PO}_{4}, 20 \mathrm{mM}$ taurine, $20 \mathrm{mM}$ HEPES, $110 \mathrm{mM}$ sucrose, $1.0 \mathrm{~g} / \mathrm{L}$ BSA essentially fatty acid free, $\mathrm{pH}$ 7.1). The fluorescence intensity was measured fluorometrically (excitation- $540 \mathrm{~nm}$ and emission- $590 \mathrm{~nm}$ ) using the Infinite M Plex microplate reader (TECAN, Switzerland). 


\section{Cellular Physiology Cell Physiol Biochem 2019;52:94-108 \\ and Biochemistry \begin{tabular}{c|c} 
DOl: $10.33594 / 000000007$ \\
Published online: 18 February 2019
\end{tabular} $\begin{aligned} & \text { O } 2019 \text { The Author(s). Published by } \\
& \text { Cel Physiol Biochem Press GmbH\&Co. KG }\end{aligned}$ \\ Shrestha et al.: Linoleic Acid Alters Viability and Mitochondrial Respiration in Trophoblasts}

Enzyme linked immune sorbent assays (ELISAs) for IL-6, PGE ${ }_{2}$ and LTB 4 estimation

Cells were treated with vehicle (BSA+EtOH) and different concentrations of LA for 24 hours. Cell culture supernatants were collected and immediately stored at $-80{ }^{\circ} \mathrm{C}$. The concentrations of interleukin- 6 (IL-6- R\&D system, MN, USA), prostaglandin $\mathrm{E}_{2}\left(\mathrm{PGE}_{2}\right.$ - Cayman chemicals, MI, USA) and leukotriene $\mathrm{B}_{4}\left(\mathrm{LTB}_{4}\right.$ Cayman chemicals) in cell culture supernatants were quantified by ELISA, according to the manufacture's protocols. For IL-6, optical density (OD) was measured at $450 \mathrm{~nm}$ in a microplate reader. A second reading at $540 \mathrm{~nm}$ was subtracted from the reading at $450 \mathrm{~nm}$ to correct for optical imperfections in the plate. $\mathrm{PGE}_{2}$ and $\mathrm{LTB}_{4}$ ELISAs were competitive assays and the absorbance was measured in microplate reader at a wavelength of $420 \mathrm{~nm}$. The concentrations in cell supernatant were calculated from the provided standard curve.

\section{Western blotting}

Protein expression was evaluated by western blotting. Briefly, protein was extracted from cells using standard RIPA buffer containing protease and phosphatase inhibitor (Sigma-Aldrich, MO, USA) and protein concentration was estimated by the BCA method using the Pierce ${ }^{\mathrm{TM}}$ BCA protein assay kit (Thermo Scientific) following manufacturer's guidelines. Samples were mixed with $5 \mathrm{X}$ Laemmli buffer, a mixture of sodium dodecyl sulfate (SDS), glycerol, Tris- $\mathrm{Cl}, \beta$-mercaptoethanol and bromophenol blue, and incubated at $95^{\circ} \mathrm{C}$ for 5 minutes. Samples were run on SDS-polyacrylamide (SDS-PAGE) gels and then transferred onto ImmobilonFL PVDF membrane (Merck Millipore, MA, USA). The membrane was blocked with Odyssey blocking buffer (LI-COR, NE, USA) for 1 hour and then incubated with primary antibodies (NF- $\mathrm{B}$ p65, 1:1000 dilution, cell signalling, Cat.no. 8242; IL-8, 1:1000 dilution, Abcam, Cat.no. ab154390; FATP1, 1:500 dilution, Abcam, Cat.no. ab69458; FATP4, 1:1000 dilution, Abcam, Cat.no. ab199719; FABP3, 1:500 dilution, Abcam, Cat.no. ab45966) at $4{ }^{\circ} \mathrm{C}$ overnight. The membrane was also incubated in a $\beta$ - actin antibody $(1: 1000$, Abcam $)$ at $4{ }^{\circ} \mathrm{C}$ for 1 hour. After incubating the membrane with primary antibody, the membrane was washed with phosphate buffered saline (PBS) plus Tween 20 (PBST) in 1X phosphate buffered saline) and then incubated with secondary antibody (IRDye $\AA$ 680LT Goat anti-Rabbit IgG; IRDye ${ }^{\circledR}$ 800CW Donkey anti-Mouse IgG- LICOR Biosciences, NE, USA) The immunoblot was then visualized via a fluorescent detection system (LI-COR Biosciences, NE, USA) and quantified using Image Studio Lite software (LI-COR Biosciences, NE, USA).

\section{Statistical analysis}

Data are expressed as mean \pm standard error (SEM). Multiple comparisons among the groups was performed by one-way ANOVA followed by the Dunnett post hoc test using GraphPad software (GraphPad, San Diego, CA). P values less than 0.05 were considered statistically significant.

\section{Results}

Linoleic acid decreases viability of Swan 71 cells

Cell viability was significantly decreased after treatment with LA compared to cells exposed to the vehicle control (Fig. 1). This was significant at all doses with modest decreases in viability at the lower doses $(\sim 10 \%$ for 100 ; $\sim 20 \%$ for $200,300,400 \mu \mathrm{M}$ ) and more severe decreases at high concentrations (34\% decrease at $500 \mu \mathrm{M}$ and $56 \%$ decrease at $1000 \mu \mathrm{M}$ ).

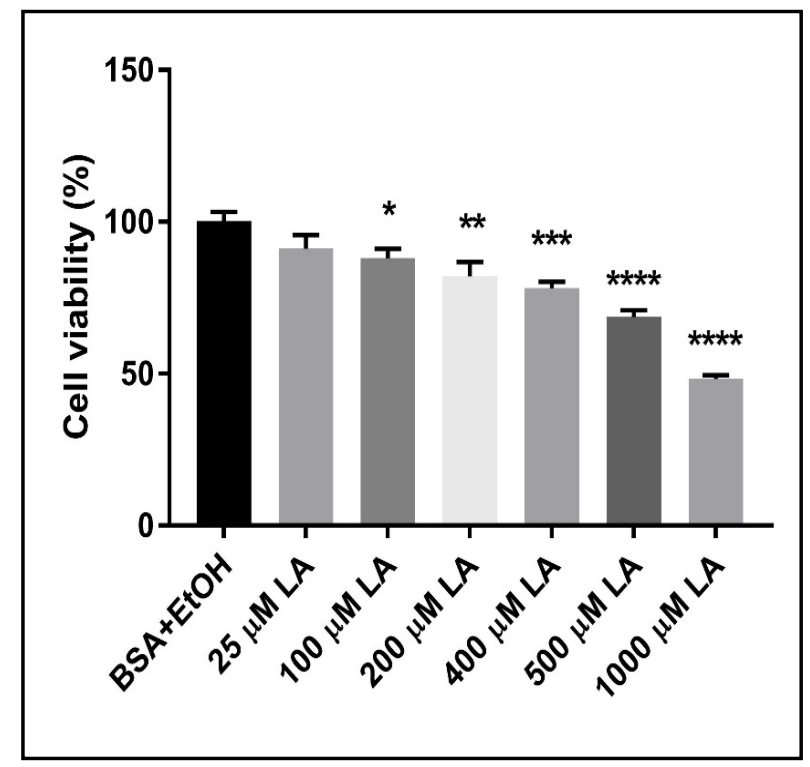

Fig. 1. Effect of linoleic acid (LA) on cellular viability Swan71 cells. LA dose dependently decreased cellular viability after 24 hours of treatment $(n=6)$. Data expressed as mean \pm SEM. ${ }^{*} \mathrm{p}<0.05,{ }^{* *} \mathrm{p}<0.01,{ }^{* * *} \mathrm{p}<0.001,{ }^{* * * *} \mathrm{p}<0.0001$ compared to vehicle control (BSA+EtOH). 
Fig. 2. Effect of linoleic acid (LA) on fatty acid transport proteins (FATPs) and fatty acid binding proteins (FABPs) expression in Swan71 cells. A,C) 300 and $500 \mu \mathrm{M}$ of LA significantly increased FATP1 and FATP4 mRNA expressions $(\mathrm{n}=6)$ and B,D) 500 $\mu \mathrm{M}$ of LA significantly increased FATP1 and FATP4 protein expression $(n=4)$. E) 100,300 and $500 \mu \mathrm{M}$ of LA significantly decreased FABP3 mRNA expression $(\mathrm{n}=6)$ and 300 and 500 $\mu \mathrm{M}$ of LA significantly decreased FABP3 protein expression $(\mathrm{n}=4) . \quad$ G) $500 \quad \mu \mathrm{M}$ of LA significantly increased mRNA expression of FABP5 $(n=6)$. Data expressed as mean \pm SEM. ${ }^{* *} \mathrm{p}<0.01,{ }^{* * *} \mathrm{p}<0.001$, $* * * * \mathrm{p}<0.0001$ compared to vehicle control (BSA+ EtOH).

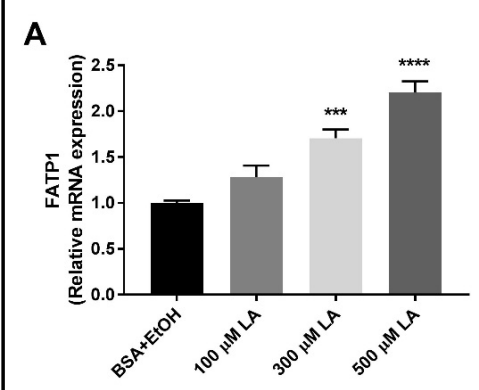

B

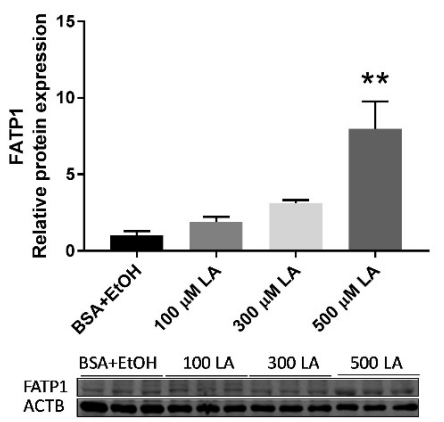

C

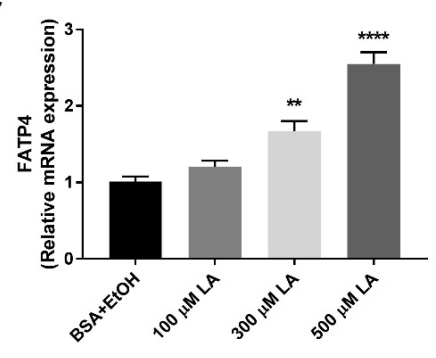

D

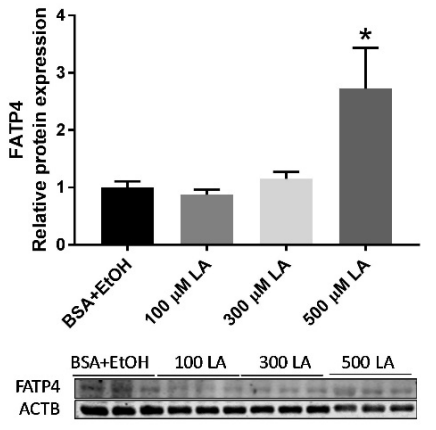

E

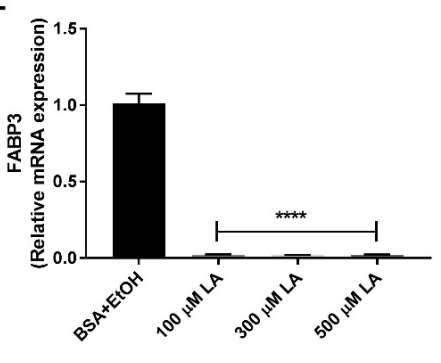

F

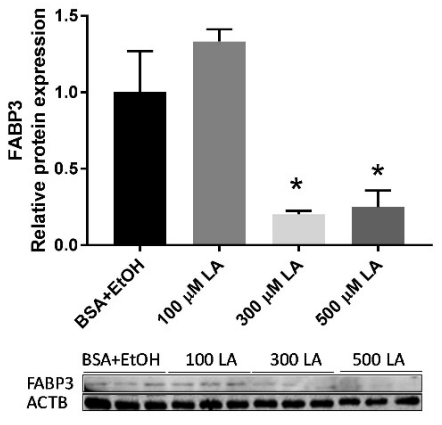

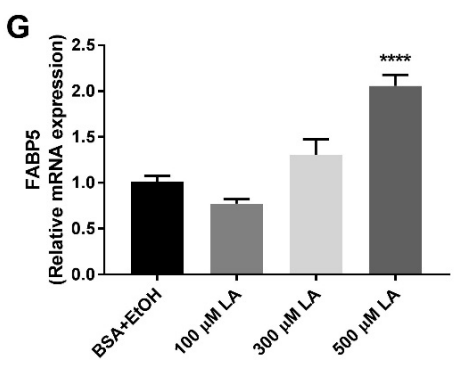

Linoleic acid alters fatty acid transporter expression in Swan71 cells

To determine if LA could affect how FAs are transported through the placenta, the mRNA expression of FATPs and FABPs was measured in Swan71 cells exposed to varying physiologically relevant concentrations of LA $(100,300$ and $500 \mu \mathrm{M}$; Fig. 2). FATP1 and FATP4 mRNA expression was increased by $300 \mu \mathrm{M}$ and $500 \mu \mathrm{M}$ of LA, and $500 \mu \mathrm{M}$ LA upregulated FATP1 and FATP4 protein expression, compared to vehicle control (Fig. 2A-D). Exposure to $100 \mu \mathrm{M}, 300 \mu \mathrm{M}$ or $500 \mu \mathrm{M}$ LA decreased FABP3 mRNA expression in comparison to the 


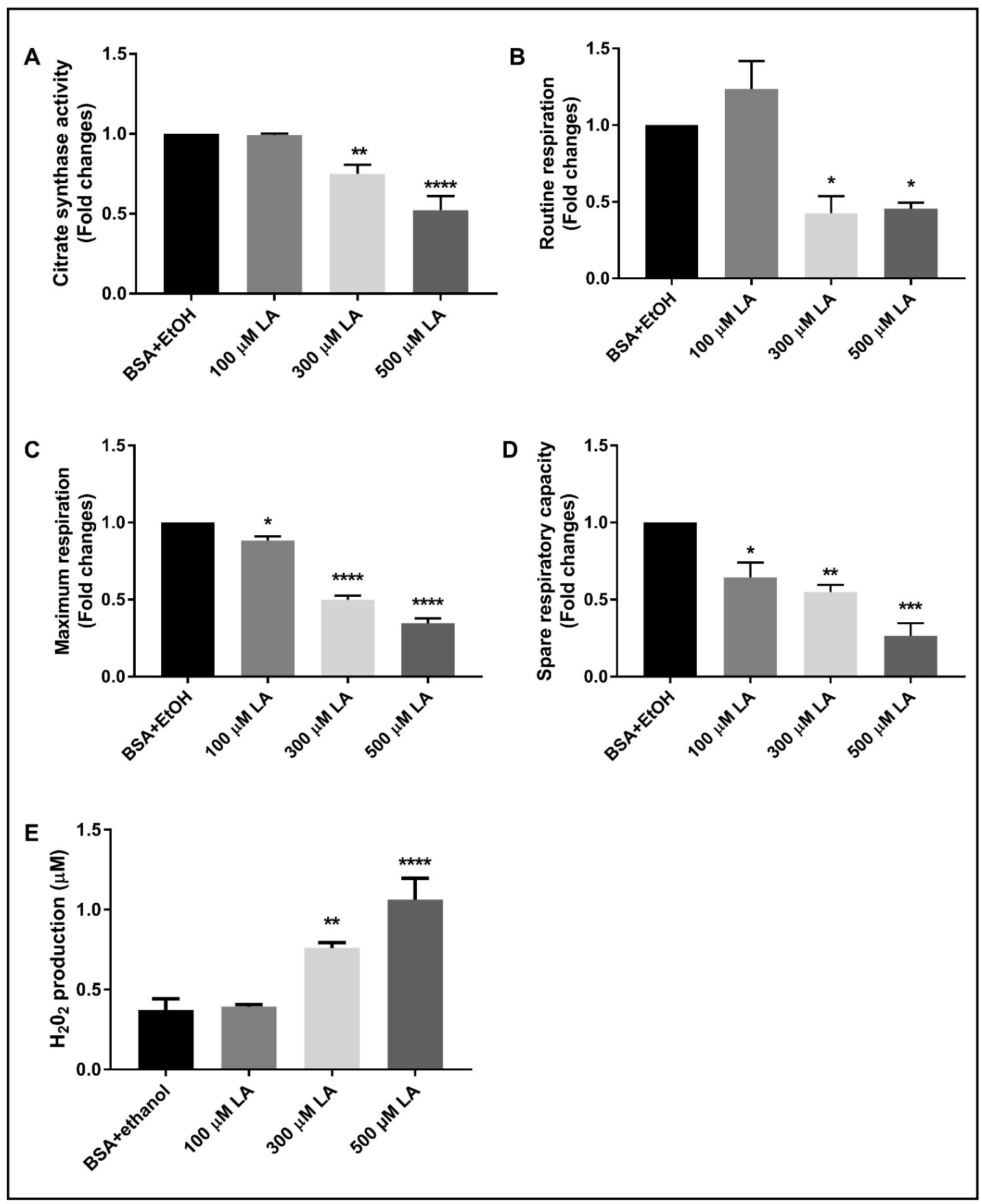

Fig. 3. Effect of linoleic acid (LA) on citrate synthase (CS) activity and cellular respiration of Swan71 cells. A) 300 and $500 \mu \mathrm{M}$ of LA significantly decreased CS activity (n=5). B) 300 and $500 \mu \mathrm{M}$ of LA significantly decreased routine respiration (n=3). C-D) 100, 300 and $500 \mu \mathrm{M}$ of LA significantly decreased maximal respiration (electron transport system (ETS) respiration) and spare respiratory capacity (n=3). E) 300 and $500 \mu \mathrm{M}$ of LA significantly increased $\mathrm{H}_{2} \mathrm{O}_{2}$ production $(\mathrm{n}=5)$. Data expressed as mean \pm SEM. ${ }^{*} \mathrm{p}<0.05$, ${ }^{* *} \mathrm{p}<0.01,{ }^{* * *} \mathrm{p}<0.001,{ }^{* * * *} \mathrm{p}<0.0001$ compared to vehicle control (BSA+EtOH). 


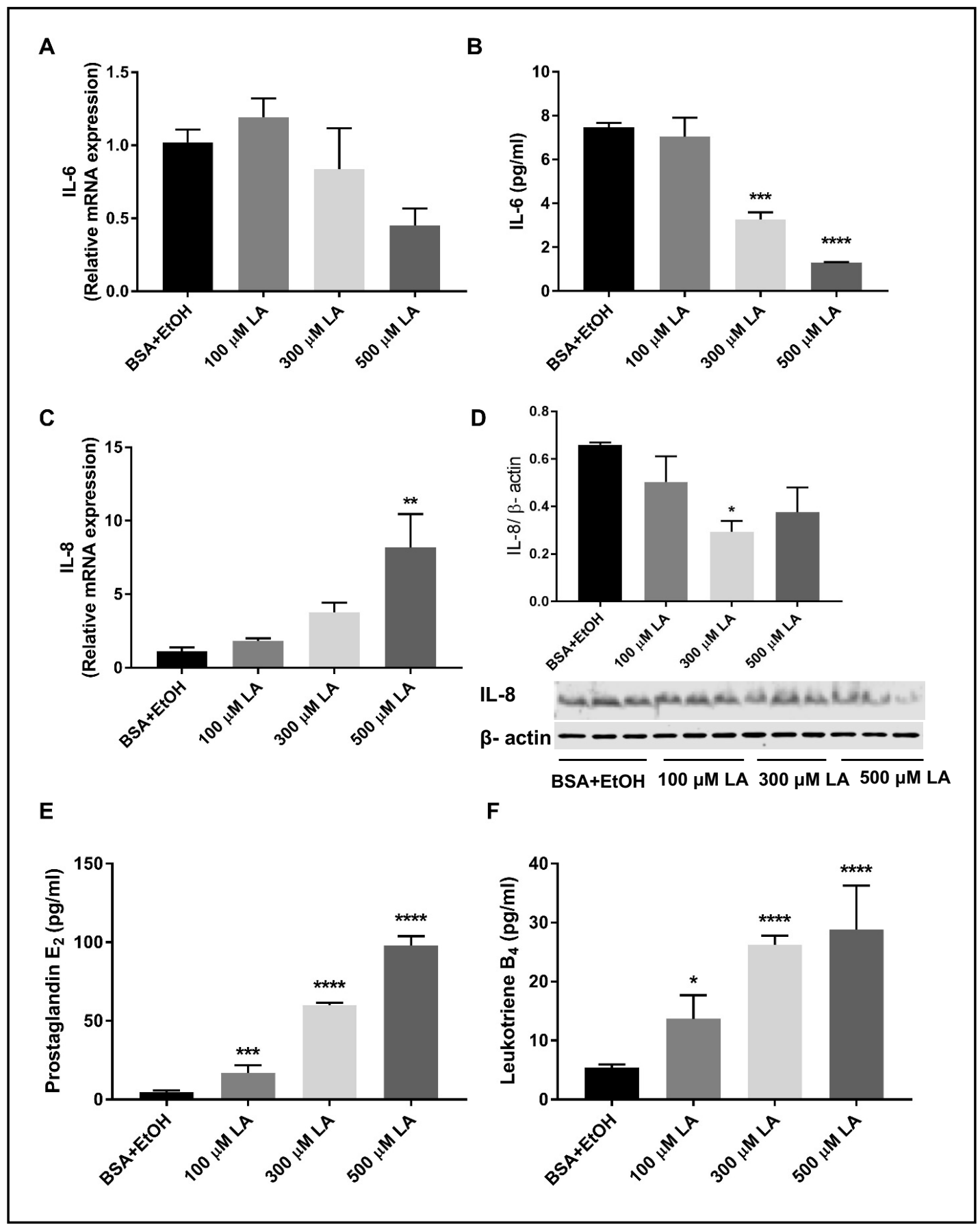

Fig. 4. Effect of linoleic acid (LA) on inflammatory responses of Swan71 cells. A) There was no significant difference in IL-6 mRNA expression between LA treated group and vehicle control group (n=6). B) 300 and $500 \mu \mathrm{M}$ of LA significantly decreased IL- 6 release in cell culture supernatant as measured by ELISA ( $n=3$ ). C) $500 \mu \mathrm{M}$ of LA of significantly increased mRNA expression of IL-8 (n=6). D) $300 \mu \mathrm{M}$ of LA of significantly decreased IL-8 protein expression ( $n=3)$. E-F) All three doses of LA significantly increased prostaglandins $\mathrm{E}_{2}$ $\left(\mathrm{PGE}_{2}\right)$ and leukotrienes $\mathrm{B}_{4}\left(\mathrm{LTB}_{4}\right)$ in cell culture supernatant $(\mathrm{n}=5)$. Data expressed as mean $\pm S E M . * p<0.05$, ${ }^{* *} \mathrm{p}<0.01,{ }^{* * *} \mathrm{p}<0.001,{ }^{* * * *} \mathrm{p}<0.0001$ compared to vehicle control (BSA+EtOH). 
vehicle control group (Fig. 2E). 300 $\mu \mathrm{M}$ or $500 \mu \mathrm{M}$ LA decreased FABP3 protein expression (Fig. 2F). 500 $\mu \mathrm{M}$ LA increased FABP5 mRNA expression (Fig. 2G). There were no changes in FATP6 and FABPpm following treatment with LA (data not shown).

Linoleic acid decreases citrate synthase activity and mitochondrial respiration, and increases ROS generation in Swan 71 cells

To investigate if the decreased cellular viability after LA treatment maybeduetomitochondrialdamage, the effect of LA on mitochondrial mass and mitochondrial respiration was measured. The mitochondrial marker enzyme citrate synthase (CS), and mitochondrial respiration under basal conditions (routine), were reduced in cells treated with 300 or $500 \mu \mathrm{M}$ of LA (CS activity: $300 \mu \mathrm{M}$ LA decreased 1.3-fold, $500 \mu \mathrm{M}$ of LA decreased 1.9-fold; routine respiration: $300 \mu \mathrm{M}$ LA decreased 2.4-fold, $500 \mu \mathrm{M}$ of LA decreased 2.2-fold; Fig. $3 \mathrm{~A}$ and B). The maximum capacity of the respiratory system (measured though addition of the uncoupling agent (CCP), and spare respiratory capacity (SRC; a measure of mitochondrial efficiency) were decreased in a dose dependent manner in cells treated with LA (maximum respiration: $100 \mu \mathrm{M}$ LA decreased 1.1-fold, $300 \mu \mathrm{M}$ LA decreased 2.0-fold, $500 \mu \mathrm{M}$ of LA decreased 2.9-fold; SRC: $100 \mu \mathrm{M}$ LA decreased 1.5-fold, $300 \mu \mathrm{M}$ LA decreased 1.8-fold, $500 \mu \mathrm{M}$ of LA decreased 3.8-fold ; Fig. 3C and D). Further, 300 and $500 \mu \mathrm{M}$ of LA increased ROS production in Swan71 cells as shown by $\mathrm{H}_{2} \mathrm{O}_{2}$ assay (Fig. 3E).

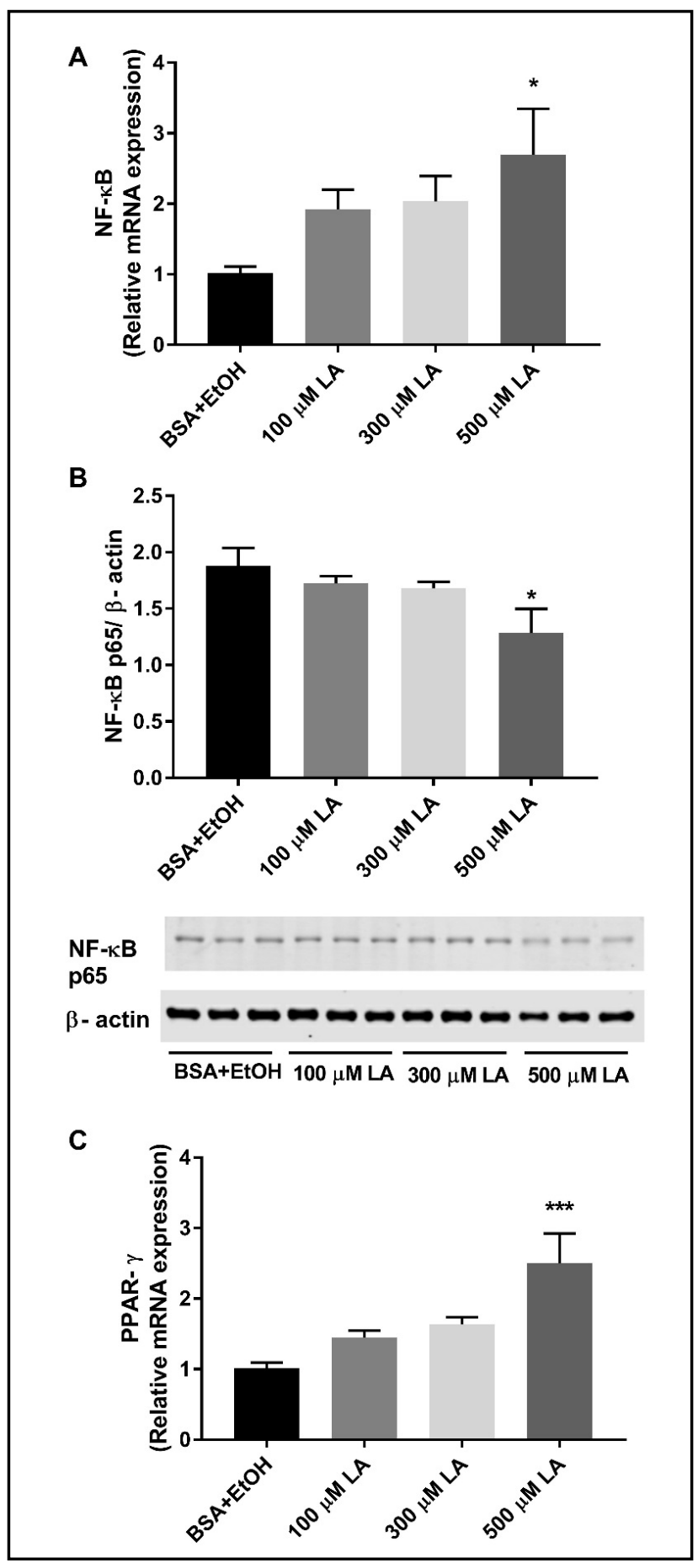

Fig. 5. Effect of linoleic acid (LA) on PPAR- $\gamma$ and NF- $\kappa B$ expressions in Swan71 cells. A) $500 \mu \mathrm{M}$ of LA significantly increased NF- $\kappa B$ mRNA expressions $(n=6)$. B) $500 \mu$ M of LA significantly decreased NF- $\kappa B$ protein expression $(n=3)$. C) $500 \mu \mathrm{M}$ of LA significantly increased PPAR- $\gamma$ mRNA expressions $(n=6)$. Data expressed as mean \pm SEM. ${ }^{*} p<0.05$, ${ }^{* * *} \mathrm{p}<0.001$ compared to vehicle control (BSA+EtOH). 


\section{Cellular Physiology Cell Physiol Biochem 2019;52:94-108 \\ \begin{tabular}{l|l|l} 
and BiOChemistry Published online: 18 February 2019 & $\begin{array}{l}\text { DO } 2019 \text { The Author(s). Published by } \\
\text { Cell Physiol Biochem Press GmbH\&Co. KG }\end{array}$
\end{tabular} \\ Shrestha et al.: Linoleic Acid Alters Viability and Mitochondrial Respiration in Trophoblasts}

Linoleic acid alters the inflammatory responses of Swan 71 cells

The effect of LA on the inflammatory response of Swan 71 cells was studied by measuring mRNA expression of inflammatory cytokines in cells, and the secretion of cytokines in cell supernatant (Fig. 4). There was no significant difference in $I L-6$ mRNA expression (Fig. $4 \mathrm{~A}$ ); however, 300 or $500 \mu \mathrm{M}$ of LA significantly decreased IL-6 protein release into the cell culture supernatant (Fig. 4B). $500 \mu \mathrm{M}$ of LA significantly elevated mRNA expression of $I L-8$ compared to the vehicle control (Fig. 4C); however, $300 \mu \mathrm{M}$ of LA decreased IL-8 protein expression (Fig. 4D). $100 \mu \mathrm{M}, 300 \mu \mathrm{M}$ or $500 \mu \mathrm{M}$ of LA significantly increased prostaglandin $\mathrm{E}_{2}\left(\mathrm{PGE}_{2}\right)$ and leukotriene $\mathrm{B}_{4}\left(\mathrm{LTB}_{4}\right)$ secretion in cell culture supernatant (Fig. 4E and F). 500 $\mu \mathrm{M}$ of LA increased mRNA expression $N F-\kappa B$ (Fig. 5A), in contrast, the protein level of NF$\kappa \mathrm{B}$ was downregulated in Swan71 cells treated with $500 \mu \mathrm{M}$ of LA (Fig. 5B). $500 \mu \mathrm{M}$ of LA increased mRNA expression of PPAR- $\gamma$ (Fig. 5C). Finally, 300 and $500 \mu \mathrm{M}$ of LA significantly increased $\mathrm{H}_{2} \mathrm{O}_{2}$ production.

\section{Discussion}

The consumption of LA is increasing worldwide. LA is essential for fetal development and must be obtained from the maternal die; however, excess maternal LA may be proinflammatory and pro-oxidative, and therefore have detrimental effects on the placenta. The key findings of our current study are that LA alters the expression of fatty acid transport related proteins, mitochondrial respiration and inflammatory responses in human placental trophoblast like cells. Given that LA significantly modifies the expression of FATP1, FATP4, FABP3 and FABP5, these proteins may be important regulators of LA transport across the trophoblast. In this study, we utilised Swan71 cells to study the effect of LA on the placenta in-vitro. Swan71 cells exhibit a cytokine and growth factor profile that is similar to primary trophoblast cells [33], making them a good in-vitro model of trophoblast response.

The placenta is a critical organ that has a wide range of roles during pregnancy, including transport of nutrients from mother to fetus [36]. Adequate FA transport through the placenta is critical for the development of a healthy fetus, and inadequate transport is linked to pregnancy related complications [37, 38]. Transport of FAs is controlled through transporters and binding proteins, which are, in part, regulated by exposure to FA [24]. The exact transporters and binding proteins required for LA transport across the placenta are unknown. In this study, we have identified several potential LA transporters that warrant further investigation. Importantly, several membrane proteins are thought to involved in fatty acid uptake, including the fatty acid translocase (FAT/CD36) [39], plasma membrane fatty acid binding protein (FABPpm) [40] and fatty acid transport proteins (FATP 1-6) [41, 42]. In the cytoplasm, FAs bind to FABPs, and are then transferred to the fetal circulation through the basal membrane [38]. We have found that FATP1, FATP4, FABP3 and FABP5 expression is modulated by LA, suggesting that these proteins may play a role in the transport of LA across the placenta. In our study, the exposure of trophoblasts to LA increased FATP1 and FATP4 expression, with no changes in FATP6 or FABPpm. FATP1 is located on the apical microvillous membrane of the placental syncytiotrophoblast that directly contacts the maternal circulation [43], whereas FATP4 expression is approximately four fold higher in the basal plasma membrane of the syncytiotrophoblast in comparison to the microvillous membrane [44]. Therefore, FATP1 and FATP4 could function to transport LA through the syncytiotrophoblast. Placental mRNA expression of FATP1 and FATP4 was correlated with docosahexaenoic acid (DHA) in maternal plasma and placental phospholipids, suggesting their involvement in placental transfer of PUFAs [41]. Further, in the current study, LA (100, 300 and $500 \mu \mathrm{M}$ ) decreased $F A B P 3$ mRNA expression by approximately $\sim 50$ fold, and $500 \mu \mathrm{M}$ of LA increased mRNA expression of $F A B P 5$ by $\sim 2$ fold. There are differences in the functions and binding activities of different FABPs, and their complex roles in trophoblast FA uptake and transport are not fully established [45]. Previous research demonstrated that in a mouse knock model of FABP3, placental transport of LA was reduced by 44\% [37]. Therefore, the 
down regulation of $F A B P 3$ observed in the current study may represent a mechanism to limit LA transport. Of note, knockout of FABP3 did not result in a complete loss of LA placental transport [37], suggesting that other FABP protein may compensate to ensure sufficient LA is transported by the placenta. Another study demonstrated that FABP3 can be modulated by other FAs. Specifically, AA stimulates FABP3 expression in BeWo choriocarcinoma trophoblastlike cells [46]. However, our novel data demonstrating that FABP3 expression is decreased by LA is supported by a study in pre-eclamptic placentas, which showed that the protein expression of FABP3 is decreased by $40 \%$ in placentas complicated by preeclampsia [46], that may be as a consequence of elevated maternal concentrations of LA [16]. Furthermore, FABP5 expression was found to be increased in placental tissue from obese diabetic women compared with placentas from obese, non-diabetic or normal weight women [47].

PUFAs are involved in cellular metabolism and various mitochondrial processes including respiratory function and ROS generation [48]. The findings from our study, when compared to work undertaken by others, demonstrates that different fatty acids impact divergent pathways in Swan71 cells. For example, palmitic acid, a saturated fatty acid, has been shown to activate a specific pro-inflammatory response through ROS generation [49], increasing IL-6 secretion [29]. Conversely, we show that LA decreased IL-6 secretion. Further, in Swan71 cells, palmitate decreased cell viability, however oleate (an unsaturated fatty acid) had no effect [50]. The findings from our studies as well as previous studies, suggest that palmitic acid and LA differentially regulate the regulators of cell viability, inflammation and antioxidant capacity [49].

In our study, LA decreased mitochondrial respiration and mitochondrial content (as measured by CS activity) in Swan71 trophoblasts independent of changes in viability, suggesting that LA damages mitochondrial function. Indeed, LA also led to increased $\mathrm{H}_{2} \mathrm{O}_{2}$ concentrations, indicating elevation of ROS as a likely mechanism of mitochondrial damage. Reduction in mitochondrial respiration and CS activity are observed in human placentae from pregnancies complicated with increased maternal adiposity [31], and mitochondrial dysfunction has been found in placenta from pregnancies suffering from pre-eclampsia $[51,52]$. Further, ROS production is reported to influence placental development, while abnormal placentation may lead to oxidative stress and pregnancy related complications $[53,54]$. Therefore, exposure to LA may lead to mitochondrial damage, and have a role in pregnancy disorders related to placental mitochondrial dysfunction. In this study, $1000 \mu \mathrm{M}$ LA reduced cell viability to $50 \%$, whereas at lower doses, LA reduced viability to $\sim 90-75 \%$. Collectively our mitochondrial respiration and hydrogen peroxide production data suggest that the surviving cells are undergoing oxidative stress. These findings are also supported by the changes in immune modulators, which are known to be affected by ROS and cellular metabolism.

The pro-inflammatory properties of LA have been extensively studied in non-pregnant individuals, but are still controversial $[10,27]$, and little work has been conducted during pregnancy. Aberrant placental inflammation is associated with placental damage; with loss of function and release of inflammatory mediators leading to fetal organ damage [28]. We demonstrate that LA modulates the production of specific pro-inflammatory cytokines in trophoblasts. Exposure to $500 \mu \mathrm{M}$ of LA increased mRNA expression of the pro-inflammatory cytokine $I L-8$, however $300 \mu \mathrm{M}$ of LA decreased protein expression of IL-8. In addition, we also observed a significant reduction in secreted IL-6. Previous research has demonstrated that $500 \mu \mathrm{M}$ of LA decreased $I L-6 \mathrm{mRNA}$ expression in primary trophoblasts, however there was no effect of LA on $I L-8$ mRNA expression [55]. Thus, the production of these cytokines by trophoblasts is differentially affected by elevated concentrations of LA. Further, LA activates prostaglandin and leukotriene production [56], which can act as pro-inflammatory molecules. Prostaglandins are produced by the phospholipase $\mathrm{A}_{2}$ / cyclooxygenase (COX) pathway, and leukotrienes are produced by the 5-lipoxygenese (LOX) pathway from AA [57]. $\mathrm{PGE}_{2}$ is one of the most abundant prostaglandins, and is associated with inflammation [58, 59]. LTB, a leukotriene, plays an important role in the host defence system against infection, however overproduction of this leukotriene cause several inflammatory related diseases [60]. In our 


\section{Cellular Physiology

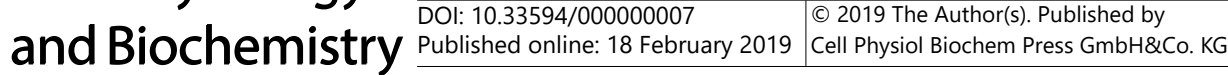 \\ Shrestha et al.: Linoleic Acid Alters Viability and Mitochondrial Respiration in Trophoblasts}

study, LA significantly increased $\mathrm{PGE}_{2}$ and $\mathrm{LTB}_{4}$ secretion from Swan71 trophoblasts. Further, $500 \mu \mathrm{M}$ of LA increased mRNA expression of $N F-\kappa B$ in our present study, however the same treatment in our study decreased NF- $\kappa B$ protein. This supports a role of LA in the regulation of NF- $\kappa \mathrm{B}$, but the differences between protein and mRNA expression are likely depends on both transcriptional and translational processes and that these may be dose dependant. Peroxisome proliferator-activated receptors (PPARs) are members of a subfamily of the nuclear receptors and are stimulated by dietary FA, as well as being involved in energy homeostasis and inflammation [61]. PPARs are expressed in the placenta [62] and activation of PPAR- $\gamma$ enhanced the expression of FATP4 and regulation of FA uptake in primary human placental trophoblasts [32], potentially via FABP5 [63]. Further, leukotrienes have the capacity to upregulate PPAR- $\gamma$ [64]. In our study, LA increased leukotrienes, PPAR- $\gamma$, FABP5 and FATP4 mRNA expression, which is congruent with previous research findings [32, 63, 64]. PPAR- $\gamma$ can upregulate inflammatory proteins, specifically IL-6 and TNF $\alpha$ [65], but also has the capacity to inhibit NF- $\kappa B$ [66]. Therefore, our study may suggest a pathway where LA increases leukotriene and FABP5, which both have the capacity to increase PPAR- $\gamma$. Activation of PPAR- $\gamma$ increases FATP4 expression [32], but decreases NF- $\kappa$ B activation [66]. Hence, our study provides evidences that elevated LA may regulate complex pathways which then modulate FA transport related proteins. Overall, these results suggest an inflammatory role of LA in the placenta.

\section{Conclusion}

In conclusion, we have shown that LA alters cell viability, expressions of FA transport associated genes, mitochondrial respiration and function, as well as inflammatory responses in the Swan71 human placental trophoblast cells line. Alteration of inflammatory response and fatty acid transporters by LA in placental cells is associated with ROS generation and PPAR- $\gamma$ upregulation. These findings suggest that the potential detrimental effects of excess LA on placental function are multi-faceted, and may have implications in pregnancy related complications. Further in-vivo studies are required to establish the exact mechanism of FA transport across the placenta, and to enhance our knowledge of appropriate intake of LA during pregnancy.

\section{Acknowledgements}

This work was supported by the Allen Foundation (DHH, AJM), and through the Australian Government's Collaborative Research Networks (CRN) program (AJM). Scholarship funding is provided by Griffith University International Postgraduate Research Scholarship (GUIPRSNS), Griffith University Postgraduate Research Scholarship (GUPRS-JSMC) and Griffith Health Top Up Scholarship (NS).

\section{Disclosure Statement}

The authors declare to have no competing interests.

\section{References}

- 1 Ramsden CE, Ringel A, Feldstein AE, Taha AY, MacIntosh BA, Hibbeln JR, Majchrzak-Hong SF, Faurot KR, Rapoport SI, Cheon Y, Chung YM, Berk M, Mann JD: Lowering dietary linoleic acid reduces bioactive oxidized linoleic acid metabolites in humans. Prostaglandins Leukot Essent Fatty Acids 2012;87:135-141. 


\section{Cellular Physiology Cell Physiol Biochem 2019;52:94-108 \begin{tabular}{ll|l}
\cline { 2 - 3 } DOI: 10.33594/000000007 & (c) 2019 The Author(s). Published by
\end{tabular} and Biochemistry Published online: 18 February 2019 Cell Physiol Biochem Press GmbH\&Co. KG

- 2 Naughton SS, Mathai ML, Hryciw DH, McAinch AJ: Australia's nutrition transition 1961-2009: a focus on fats. Br J Nutr 2015;114:337-346.

- 3 Blasbalg TL, Hibbeln JR, Ramsden CE, Majchrzak SF, Rawlings RR: Changes in consumption of omega-3 and omega-6 fatty acids in the United States during the 20th century. Am J Clin Nutr 2011;93:950-962.

- 4 Sardesai VM: The essential fatty acids. Nutr Clin Pract 1992;7:179-186.

- 5 Ramsden CE, Zamora D, Leelarthaepin B, Majchrzak-Hong SF, Faurot KR, Suchindran CM, Ringel A, Davis JM, Hibbeln JR: Use of dietary linoleic acid for secondary prevention of coronary heart disease and death: evaluation of recovered data from the Sydney Diet Heart Study and updated meta-analysis. BMJ 2013;346:e8707.

6 Williams CD, Whitley BM, Hoyo C, Grant DJ, Iraggi JD, Newman KA, Gerber L, Taylor LA, McKeever MG, Freedland SJ: A high ratio of dietary n-6/n-3 polyunsaturated fatty acids is associated with increased risk of prostate cancer. Nutr Res 2011;31:1-8.

7 Abdelmagid SA, Clarke SE, Nielsen DE, Badawi A, El-Sohemy A, Mutch DM, Ma DW: Comprehensive profiling of plasma fatty acid concentrations in young healthy Canadian adults. PloS One 2015;10:e116195.

8 Choque B, Catheline D, Rioux V, Legrand P: Linoleic acid: between doubts and certainties. Biochimie 2014;96:14-21.

9 Whelan J, Fritsche K: Linoleic acid. Adv Nutr 2013;4:311-312.

- 10 Marchix J, Choque B, Kouba M, Fautrel A, Catheline D, Legrand P: Excessive dietary linoleic acid induces proinflammatory markers in rats. J Nutr Biochem 2015;26:1434-1441.

11 Alvheim AR, Malde MK, Osei-Hyiaman D, Lin YH, Pawlosky RJ, Madsen L, Kristiansen K, Froyland L, Hibbeln JR: Dietary linoleic acid elevates endogenous 2-AG and anandamide and induces obesity. Obesity 2012;20:1984-1994.

12 Gluckman PD, Hanson MA, Cooper C, Thornburg KL: Effect of in utero and early-life conditions on adult health and disease. N Engl J Med 2008;359:61-73.

13 Barker DJ: The intrauterine origins of cardiovascular disease. Acta Paediatr Suppl 1993;391:93-99.

- 14 Cheong JN, Wlodek ME, Moritz KM, Cuffe JS: Programming of maternal and offspring disease: impact of growth restriction, fetal sex and transmission across generations. J Physiol 2016;594:4727-4740.

15 Kabaran S, Besler HT: Do fatty acids affect fetal programming? J Health Popul Nutr 2015;33:14.

- 16 Villa PM, Laivuori H, Kajantie E, Kaaja R: Free fatty acid profiles in preeclampsia. Prostaglandins Leukot Essent Fatty Acids 2009;81:17-21.

17 Chen X, Scholl TO, Leskiw M, Savaille J, Stein TP: Differences in maternal circulating fatty acid composition and dietary fat intake in women with gestational diabetes mellitus or mild gestational hyperglycemia. Diabetes Care 2010;33:2049-2054.

18 Phelps RL, Metzger BE, Freinkel N: Carbohydrate metabolism in pregnancy. XVII. Diurnal profiles of plasma glucose, insulin, free fatty acids, triglycerides, cholesterol, and individual amino acids in late normal pregnancy. Am J Obstet Gynecol 1981;140:730-736.

19 Courville AB, Keplinger MR, Judge MP, Lammi-Keefe CJ: Plasma or red blood cell phospholipids can be used to assess docosahexaenoic acid status in women during pregnancy. Nutr Res 2009;29:151-155.

20 Mackay VA, Huda SS, Stewart FM, Tham K, McKenna LA, Martin I, Jordan F, Brown EA, Hodson L, Greer IA, Meyer BJ, Freeman DJ: Preeclampsia is associated with compromised maternal synthesis of long-chain polyunsaturated fatty acids, leading to offspring deficiency. Hypertension 2012;60:1078-1085.

21 Haggarty P: Placental regulation of fatty acid delivery and its effect on fetal growth--a review. Placenta 2002;23:S28-38.

22 Perazzolo S, Hirschmugl B, Wadsack C, Desoye G, Lewis RM, Sengers BG: The influence of placental metabolism on fatty acid transfer to the fetus. J Lipid Res 2017;58:443-454.

23 Duttaroy AK: Transport of fatty acids across the human placenta: A review. Prog Lipid Res 2009;48:52-61.

24 Black PN, Sandoval A, Arias-Barrau E, DiRusso CC: Targeting the fatty acid transport proteins (FATP) to understand the mechanisms linking fatty acid transport to metabolism. Immunology, Endocr Metab Agents Med Chem 2009;9:11-17.

- 25 Lager S, Powell TL: Regulation of nutrient transport across the placenta. J Pregnancy 2012;2012:179827.

- 26 Dutta-Roy AK: Cellular uptake of long-chain fatty acids: role of membrane-associated fatty-acid-binding/ transport proteins. Cell Mole Life Sci 2000;57:1360-1372.

27 Toborek M, Lee YW, Garrido R, Kaiser S, Hennig B: Unsaturated fatty acids selectively induce an inflammatory environment in human endothelial cells. Am J Clin Nutr 2002;75:119-125. 


\section{Cellular Physiology Cell Physiol Biochem 2019;52:94-108 \begin{tabular}{c|l}
\cline { 2 - 3 } DOI: 10.33594/000000007 & (c) 2019 The Author(s). Published by
\end{tabular} and Biochemistry Published online: 18 February 2019 Cell Physiol Biochem Press GmbH\&Co. KG

- 28 Redline RW: Placental inflammation. Semin Neonatol 2004;9:265-274.

- 29 Shirasuna K, Takano H, Seno K, Ohtsu A, Karasawa T, Takahashi M, Ohkuchi A, Suzuki H, Matsubara S, Iwata H, Kuwayama T: Palmitic acid induces interleukin-1beta secretion via NLRP3 inflammasomes and inflammatory responses through ROS production in human placental cells. J Reprod Immunol 2016;116:104-112.

30 Gulliver CE, Friend MA, King BJ, Robertson SM, Wilkins JF, Clayton EH: Increased prostaglandin response to oxytocin in ewes fed a diet high in omega- 6 polyunsaturated fatty acids. Lipids 2013;48:177-183.

31 Mele J, Muralimanoharan S, Maloyan A, Myatt L: Impaired mitochondrial function in human placenta with increased maternal adiposity. Am J Physiol Endocrinol Metabol 2014;307:E419-425.

32 Schaiff WT, Bildirici I, Cheong M, Chern PL, Nelson DM, Sadovsky Y: Peroxisome proliferator-activated receptor-gamma and retinoid $\mathrm{X}$ receptor signaling regulate fatty acid uptake by primary human placental trophoblasts. J Clin Endocrinol Metab 2005;90:4267-4275.

33 Straszewski-Chavez SL, Abrahams VM, Alvero AB, Aldo PB, Ma Y, Guller S, Romero R, Mor G: The isolation and characterization of a novel telomerase immortalized first trimester trophoblast cell line, Swan 71. Placenta 2009;30:939-948.

34 Eigentler A, Draxl A, Wiethüchter A, Kuznetsov A, Lassing B, Gnaiger E: Laboratory Protocol: Citrate synthase a mitochondrial marker enzyme. Mitochondrial Physiology Network 2015;17:1-11.

- 35 Strober W: Trypan blue exclusion test of cell viability. Curr Protocol Immunol 2001; DOI: 10.1002/0471142735.ima03bs21.

- 36 Burton GJ, Fowden AL: The placenta: a multifaceted, transient organ. Philos Trans R Soc Lond B Biol Sci 2015;370:20140066.

37 Islam A, Kagawa Y, Sharifi K, Ebrahimi M, Miyazaki H, Yasumoto Y, Kawamura S, Yamamoto Y, Sakaguti S, Sawada T, Tokuda N, Sugino N, Suzuki R, Owada Y: Fatty Acid Binding Protein 3 Is Involved in n-3 and n-6 PUFA transport in mouse trophoblasts. J Nutr 2014;144:1509-1516.

38 Cetin I, Parisi F, Berti C, Mando C, Desoye G: Placental fatty acid transport in maternal obesity. J Dev Orig Health Dis 2012;3:409-414.

39 Abumrad NA, el-Maghrabi MR, Amri EZ, Lopez E, Grimaldi PA: Cloning of a rat adipocyte membrane protein implicated in binding or transport of long-chain fatty acids that is induced during preadipocyte differentiation. Homology with human CD36. J Biol Chem 1993;268:17665-17668.

40 Stremmel W, Strohmeyer G, Borchard F, Kochwa S, Berk PD: Isolation and partial characterization of a fatty acid binding protein in rat liver plasma membranes. Proc Natl Acad Sci 1985;82:4-8.

- 41 Larque E, Krauss-Etschmann S, Campoy C, Hartl D, Linde J, Klingler M, Demmelmair H, Cano A, Gil A, Bondy B, Koletzko B: Docosahexaenoic acid supply in pregnancy affects placental expression of fatty acid transport proteins. Am J Clin Nutr 2006;84:853-861.

- 42 Diaz P, Harris J, Rosario FJ, Powell TL, Jansson T: Increased placental fatty acid transporter 6 and binding protein 3 expression and fetal liver lipid accumulation in a mouse model of obesity in pregnancy. Am J Physiol Regul Integ Comp Physiol 2015;309:R1569-1577.

- 43 Hirschmugl B, Desoye G, Catalano P, Klymiuk I, Scharnagl H, Payr S, Kitzinger E, Schliefsteiner C, Lang U, Wadsack C, Hauguel-de Mouzon S: Maternal obesity modulates intracellular lipid turnover in the human term placenta. Int J Obes (London) 2017;41:317-323.

- 44 Lager S, Ramirez VI, Gaccioli F, Jang B, Jansson T, Powell TL: Protein expression of fatty acid transporter 2 is polarized to the trophoblast basal plasma membrane and increased in placentas from overweight/obese women. Placenta 2016;40:60-66.

45 Duttaroy AK: Transport of fatty acids across the human placenta: a review. Progr Lipid Res 2009;48:52-61.

- 46 Leroy C, Tobin KAR, Basak S, Cathrine Staff A, Duttaroy AK: Fatty acid-binding protein3 expression in BeWo cells, a human placental choriocarcinoma cell line. Prostaglandins Leukotr Essent Fatty Acids 2017;120:17.

- 47 Scifres CM, Chen B, Nelson DM, Sadovsky Y: Fatty acid binding protein 4 regulates intracellular lipid accumulation in human trophoblasts. J Clin Endocrinol Metab 2011;96:E1083-1091.

- 48 Rohrbach S: Effects of dietary polyunsaturated fatty acids on mitochondria. Curr Pharm Des 2009;15:41034116.

- 49 Manuel CR, Charron MJ, Ashby CR, Jr., Reznik SE: Saturated and unsaturated fatty acids differentially regulate in vitro and ex vivo placental antioxidant capacity. Am J Repro Immunol 2018:e12868. 


\section{Cellular Physiology Cell Physiol Biochem 2019;52:94-108 \begin{tabular}{ll|l|l|l}
\hline DOI: 10.33594/000000007 & (O)19 The Author(s). Published by
\end{tabular} and Biochemistry

- 50 Hong YJ, Ahn HJ, Shin J, Lee JH, Kim JH, Park HW, Lee SK: Unsaturated fatty acids protect trophoblast cells from saturated fatty acid-induced autophagy defects. J Reprod Immunol 2018;125:56-63.

51 Vishnyakova PA, Volodina MA, Tarasova NV, Marey MV, Tsvirkun DV, Vavina OV, Khodzhaeva ZS, Kan NE, Menon R, Vysokikh MY, Sukhikh GT: Mitochondrial role in adaptive response to stress conditions in preeclampsia. Sci Rep 2016;6:32410.

- 52 Holland O, Dekker Nitert M, Gallo LA, Vejzovic M, Fisher JJ, Perkins AV: Review: Placental mitochondrial function and structure in gestational disorders. Placenta 2017;54:2-9.

- 53 Wu F, Tian FJ, Lin Y, Xu WM: Oxidative Stress: Placenta Function and Dysfunction. Am J Reprod Immunol 2016;76:258-271.

54 Cuffe JS, Xu ZC, Perkins AV: Biomarkers of oxidative stress in pregnancy complications. Biomarkers Med 2017;11:295-306.

55 Yang X, Haghiac M, Glazebrook P, Minium J, Catalano PM, Hauguel-de Mouzon S: Saturated fatty acids enhance TLR4 immune pathways in human trophoblasts. Hum Reprod 2015;30:2152-2159.

56 Marion-Letellier R, Savoye G, Ghosh S: Polyunsaturated fatty acids and inflammation. IUBMB Life 2015;67:659-667.

57 Yoshikai Y: Roles of prostaglandins and leukotrienes in acute inflammation caused by bacterial infection. Curr Opin Infect Dis 2001;14:257-263.

- 58 Ricciotti E, FitzGerald GA: Prostaglandins and inflammation. Arterioscler Thromb Vasc Biol 2011;31:9861000.

59 Zhuang Y, Zhao F, Liang J, Deng X, Zhang Y, Ding G, Zhang A, Jia Z, Huang S: Activation of COX-2/mPGES-1/ PGE2 Cascade via NLRP3 Inflammasome Contributes to Albumin-Induced Proximal Tubule Cell Injury. Cell Physiol Biochem 2017;42:797-807.

-60 Toda A, Yokomizo T, Shimizu T: Leukotriene B4 receptors. Prostaglandins Other Lipid Mediat 2002;6869:575-585.

- 61 Varga T, Czimmerer Z, Nagy L: PPARs are a unique set of fatty acid regulated transcription factors controlling both lipid metabolism and inflammation. Bioch Biophys Acta 2011;1812:1007-1022.

62 Wang Q, Fujii H, Knipp GT: Expression of PPAR and RXR isoforms in the developing rat and human term placentas. Placenta 2002;23:661-671.

63 Bao Z, Malki MI, Forootan SS, Adamson J, Forootan FS, Chen D, Foster CS, Rudland PS, Ke Y: A novel cutaneous Fatty Acid-binding protein-related signaling pathway leading to malignant progression in prostate cancer cells. Genes Cancer 2013;4:297-314.

64 Paruchuri S, Jiang Y, Feng C, Francis SA, Plutzky J, Boyce JA: Leukotriene E4 activates peroxisome proliferator-activated receptor gamma and induces prostaglandin D2 generation by human mast cells. J Biol Chem 2008;283:16477-16487.

65 Takata Y, Kitami Y, Yang ZH, Nakamura M, Okura T, Hiwada K: Vascular inflammation is negatively autoregulated by interaction between CCAAT/enhancer-binding protein-delta and peroxisome proliferator-activated receptor-gamma. Circ Res 2002;91:427-433.

- 66 Wahli W, Michalik L: PPARs at the crossroads of lipid signaling and inflammation. Trends Endocrinol Metab 2012;23:351-363. 